\title{
CHANGE DETECTION FOR TRAFFIC MONITORING IN TERRASAR-X IMAGERY
}

\author{
Gintautas Palubinskas and Hartmut Runge \\ German Aerospace Center DLR \\ Remote Sensing Technology Institute \\ Münchener Str. 20, 82234 Wessling, Germany \\ Gintautas.Palubinskas@dlr.de
}

\begin{abstract}
In this paper the changes occurring in two images acquired at two different time moments are analyzed. In particular the interest is in the changes of filling grade of car-parks or even detecting stopped vehicles on the congested or jammed roads. As input to the change detection processor can serve two repeat-pass single channel images acquired by any airborne or space borne SAR satellite sensor. Each channel is focused, calibrated and processed to a single look slant range complex SAR image. The proposed change detection approach is based on the combination of various techniques: co-registration of two SAR images by interferometric SAR processor, removal of the flat Earth phase, channel balancing, calculating of a coherent or incoherent difference of two images and finally image post-processing and analysis. First experiments on TerraSAR-X imagery show promising results.
\end{abstract}

Index Terms - Change detection, repeat-pass SAR images, traffic monitoring, TerraSAR-X, car-parks

\section{INTRODUCTION}

During the past years, increasing traffic appears to be one of the major problems in urban and sub-urban areas [1]. Traffic monitoring e.g. detection of congestion and jams, observing filling grade of park \& ride car-parks and so on is becoming more and more important. A new type of information is needed for a more efficient use of road networks. Remote sensing sensors installed on aircrafts or satellites enable data collection on a large scale and thus seem to be very suitable for various traffic monitoring applications. Optical systems are already in experimental use, e.g. 3K camera system [2, 3], but are quite limited due to their daylight operation and cloud-free conditions requirements. Synthetic aperture radar (SAR) sensors due to their all-weather capabilities seem to be well suited for such type of applications. For example, the German radar satellite TerraSAR-X launched on June 15, 2007 acquires high resolution images [4] which are very well suitable for various traffic monitoring applications [5].

\section{METHOD}

Change analysis in two images acquired at two different time moments can be very useful in estimating the filling grade of car-parks or even detecting stopped vehicles on the congested or jammed roads. For example, such inputs to the change detection processor are two repeat-pass single channel images of TerraSAR-X sensor. Each channel is focused, calibrated and single look slant range complex SAR image (SLC). Our change detection approach is based on the combination of various techniques: co-registration of two SAR images by interferometric SAR processor [6], removal of the flat Earth phase, channel balancing [7], coherent or incoherent difference of two images and finally image post-processing and analysis.

\section{EXPERIMENTS}

To validate the method three stacks of TerraSAR-X data were acquired under the same imaging conditions. RGB images have been used for the analysis and interpretation of the changes.

\subsection{Data}

The first data stack covers the city of Munich in Southern Germany and consists of 3 images acquired in StripMap mode SM, HH polarization, descending orbit, azimuth resolution $3 \mathrm{~m}$, slant range resolution $1.2 \mathrm{~m}$, incidence angle $41^{\circ}$ acquired on June 26th 2007, July 7th 2007 and August 20th 2007 at 7:26 local time.

The second data stack is near the Salisbury city in England and consists of 2 images acquired in Spotlight mode HS, range bandwidth $300 \mathrm{MHz}$, VV polarization, ascending orbit, azimuth resolution $0.9 \mathrm{~m}$, slant range resolution 0.6 $\mathrm{m}$, incidence angle $40^{\circ}$ acquired on October 19th 2007 and November 21st 2007 at 17:52 UTC time.

The third data stack covers again the city of Munich in Southern Germany and consists of 2 images acquired in Spotlight mode HS, range bandwidth $300 \mathrm{MHz}$, VV polarization, ascending orbit, azimuth resolution $1.3 \mathrm{~m}$, 
slant range resolution $0.6 \mathrm{~m}$, incidence angle $23^{\circ}$ acquired on January 24th 2008 and February 15th 2008 at 17:51 UTC time.

\subsection{Results}

Preliminary results show the potential of the proposed method for the change detection of stopped vehicles (Fig. 1), parking vehicles on street sides (Fig. 2), parking vehicles in large car-parks (Fig. 3) and slowly moving vehicles on the roads (Fig. 4) in repeat-pass SAR scenes. Google images are used as a reference.
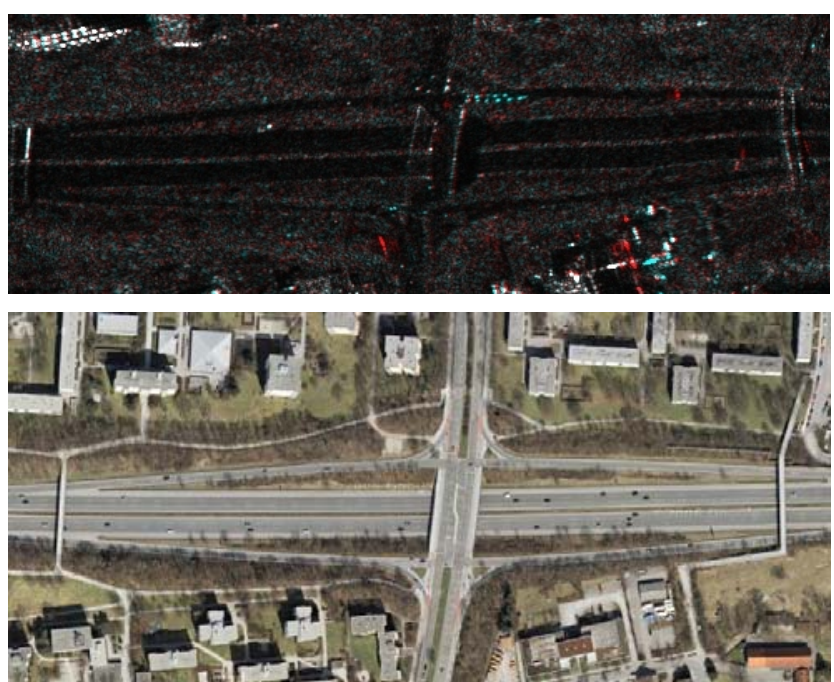

Fig. 1 Stopped vehicles (e.g. blue points) at the traffic lights after leaving the highway A96 (upper image, stack no. 3).
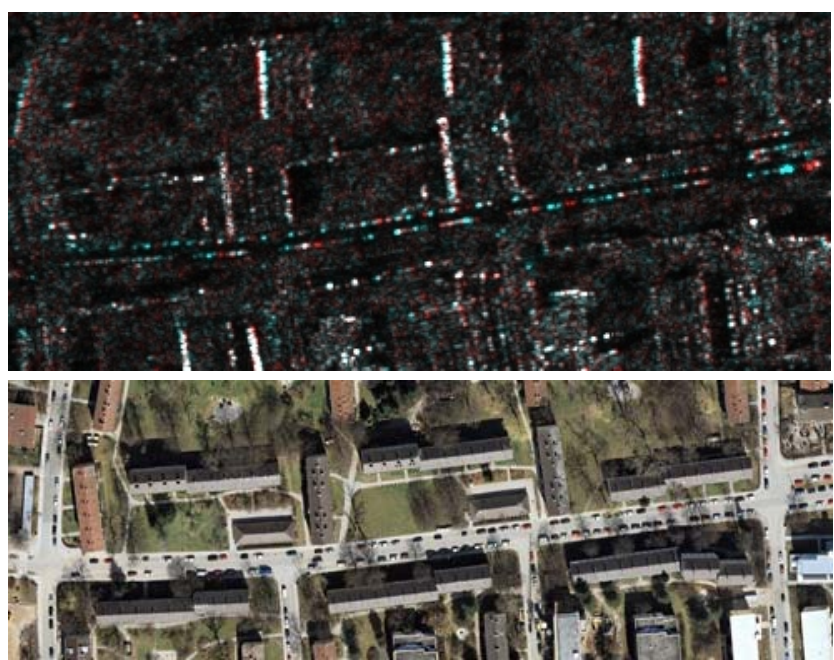

Fig. 2 Parking vehicles (blue or red points) at the sides of the street aligned horizontally (upper image, stack no. 3).

\section{DISCUSSION}

For monitoring of smaller car-parks high resolution modes of the sensor such as high resolution Spotlight (HS) may be needed. A priori information such as the boundaries of carparks, e.g. from Geographical Information Systems (GIS) or road network, e.g. road data base NAVTEQ [8] is necessary in order to automatize the whole process. Improvement of the change detection process by the combination of various techniques: co-registration of two SAR images by interferometric SAR processor, removal of the flat Earth phase, channel balancing, calculating of a coherent or incoherent difference of two images and finally image postprocessing is currently under investigation. Of course, the method is not limited to only repeat-pass TerraSAR-X images. It can be applied to any SAR images acquired at two different times.

\section{CONCLUSION}

In this paper change detection analysis for a pairs of images acquired at two different time moments is presented. First experiments on TerraSAR-X imagery show promising results by detecting changes of filling grade of car-parks or even detecting stopped vehicles on the congested or jammed roads.

\section{AKNOWLEGMENT}

The good visibility of traffic jams in TSX Spotlight images has been pointed out to the authors by their colleague Thomas Fritz.

\section{REFERENCES}

[1] http://ops.fhwa.dot.gov/congestion report/ (Accessed on June 10, 2008).

[2] P. Reinartz, M. Lachaise, E. Schmeer, T. Krauß, and H. Runge, "Traffic Monitoring with Serial Images from Airborne Cameras", ISPRS Journal of Photogrammetry and Remote Sensing, vol. 61, pp. 149-158, 2006.

[3] G. Palubinskas, F. Kurz, and P. Reinartz, "Detection of traffic congestion in optical remote sensing imagery", Proc. IGARSS, Boston, USA, 2008.

[4] M. Eineder, B. Schättler, H. Breit, T. Fritz, and A. Roth, "TerraSAR-X SAR products and processing algorithms", Proc. IGARSS, Seoul, Korea, 2005.

[5] F. Meyer, S. Hinz, R. Müller, G. Palubinskas, C. Laux, and H. Runge, "Towards traffic monitoring with TerraSAR-X”, Canadian Journal of Remote Sensing, vol. 33, no. 1, pp. 39-51, 2007.

[6] N. Adam, M. Eineder, H. Breit, and S. Suchandt, "Shuttle Radar Topography Mission: DLR's Interferometric SAR Processor for the Generation of a Global Digital Elevation Model”, European Space Agency, (Special Publication) ESA SP (478), pp. 91-98, 2000. 
[7] C.H. Gierull, "Digital channel balancing of interferometric SAR data”, Technical Memorandum TM 2003-024, Defence Research and Development Canada, Ottawa, March, 2003.
[8] http://www.navteq.com/about/data.html (Accessed on June 10, 2008).

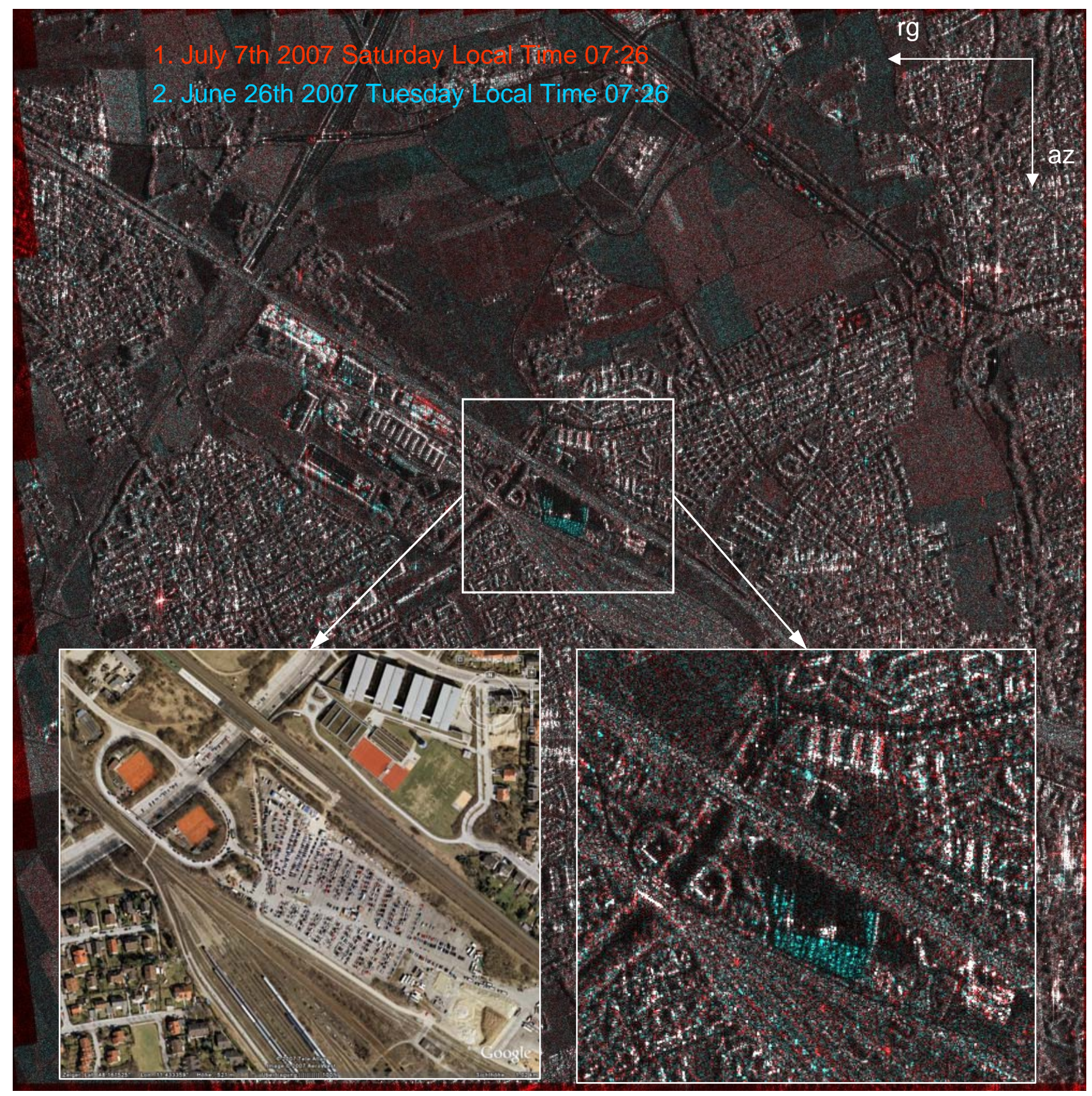

Fig. 3 Example of change detection in car-parks is presented as RGB image (Red: Saturday July 7th 2007, Blue: Tuesday June 26th 2007, both local time 7:26) for TerraSAR-X (StripMap, HH, descending orbit, azimuth resolution 3m, slant range resolution 1.2m, incidence angle $41^{\circ}$ ) over Munich, Germany. We can see clearly how the car-park is half filled on the working day (blue color) in comparison with a weekend. The marked area is zoomed in the lower part of the image (left is a Google image used as a reference image). 


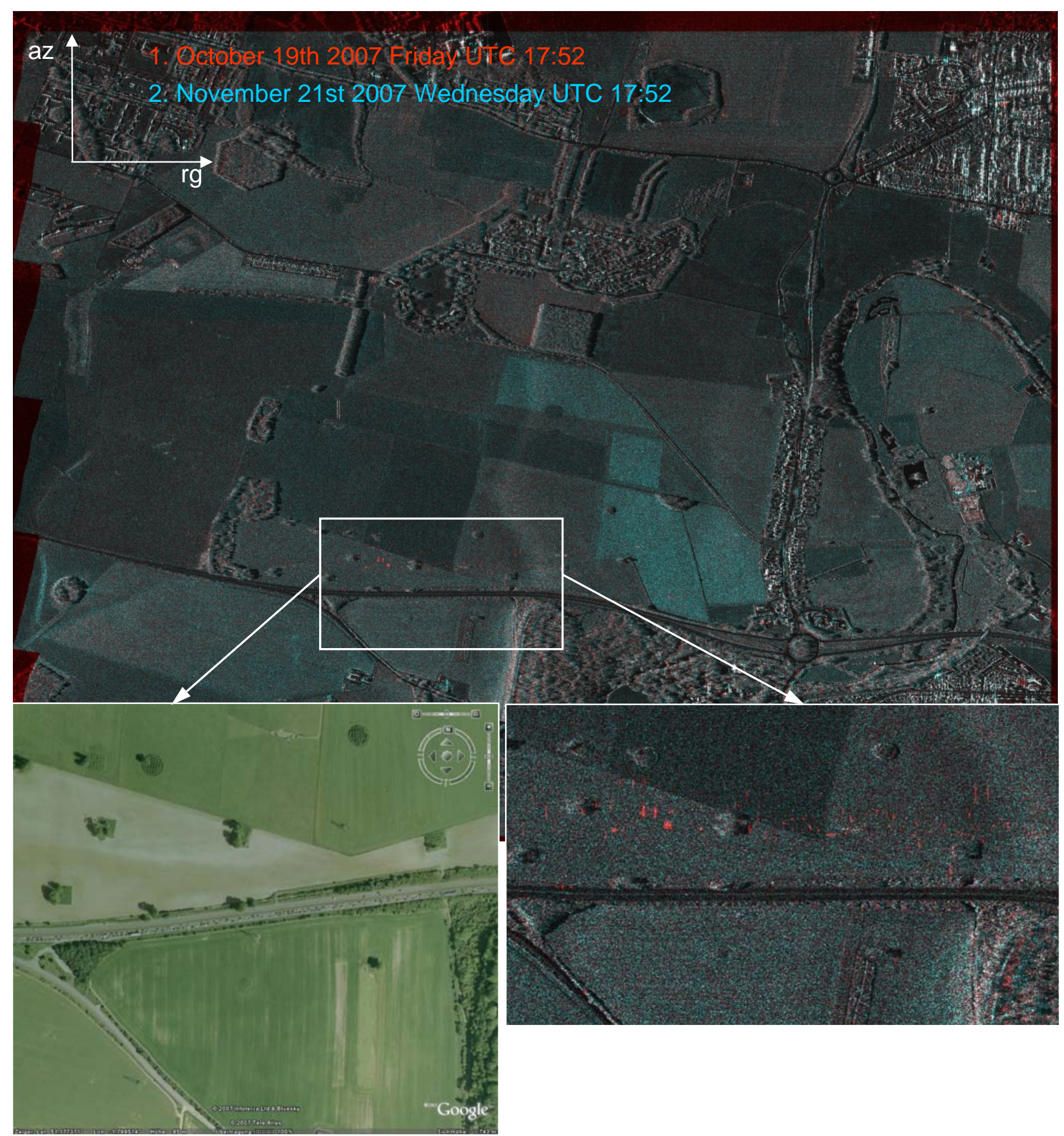

Fig. 4 Example of change detection of slowly moving vehicles on the road is presented as RGB image (Red: Friday October 19 th 2007 UTC 17:52, Blue: Wednesday November 21st 2007 UTC 17:52) for TerraSAR-X (Spotlight HS, range bandwidth 300MHz, HH, ascending orbit, azimuth resolution $0.9 \mathrm{~m}$, slant range resolution $0.6 \mathrm{~m}$, incidence angle $40^{\circ}$ ) near Salisbury, England. We can see clearly moving vehicles displaced in azimuth driving from the right to the left at the end of the last working day in the week (red color) in comparison with a middle day of the week. The marked area is zoomed in the lower part of the image (left is a Google image used as a reference image). 